\title{
Case Series of Mullerian Developmental Defects Encountered in a Tertiary Care Hospital: A One-Year Experience
}

\author{
Indranil Banerjee ${ }^{1 *}$, Suresh Chandra Mondal1, Purvita Dam², Prasanna Roy ${ }^{3}$ \\ ${ }^{1}$ Malda Medical College, Malda, India \\ ${ }^{2}$ North Bengal Medical College, Siliguri, India \\ ${ }^{3}$ ESI Hospitals, Asansol, India \\ Email: ${ }^{\text {indranil md@yahoo.com }}$
}

Received 22 June 2014; revised 18 July 2014; accepted 15 August 2014

Copyright (C) 2014 by authors and Scientific Research Publishing Inc.

This work is licensed under the Creative Commons Attribution International License (CC BY).

http://creativecommons.org/licenses/by/4.0/

c) (i) Open Access

\begin{abstract}
Congenital anomalies of the female reproductive tract may involve the uterus, cervix, fallopian tubes, or vagina. Depending on the specific defect, a woman's obstetric and gynecologic health may be adversely affected. In the present series patients presenting in the outpatient department with diagnosed Mullerian abnormalities were classified into several categories based on their presenting complaints. These patients were offered proper judicious management and were followed up as required. After one year of study period it was clear that most of these patients (barring a few exceptions) were treated optimally and they could live a healthy lifestyle thereafter.
\end{abstract}

\section{Keywords}

Mullerian, Agenesis, Rectal, Unicornuate, Bicornuate, Septum

\section{Introduction}

The Mullerian ducts are paired ducts that form the epithelial lining of the female reproductive organs. These ducts are also known as paramesonephric ducts as they lie beside the mesonephric (Wolfian) ducts. Mullerian ducts are the primordial analogue of the female reproductive tract which differentiates to form the fallopian tubes, cervix, body of uterus and the upper part of vagina. Mullerian developmental anomalies result mainly due to a wide variety of embryological disruption that affects the system [1]. According to the site \& type of the defect, the AFS has classified the Mullerian developmental defects into following types and subtypes (Figure 1, Figure 2).

*Corresponding author.

How to cite this paper: Banerjee, I., Mondal, S.C., Dam, P. and Roy, P. (2014) Case Series of Mullerian Developmental Defects Encountered in a Tertiary Care Hospital: A One-Year Experience. Open Journal of Obstetrics and Gynecology, 4, 733-744. http://dx.doi.org/10.4236/ojog.2014.413102 
1988 AFS Classification of Mullerian anomalies.

(b) Cervical

Figure 1. AFS classification of Mullerian anomalies [2].

\section{AIMS and Objectives}

1) Account the various clinical presentations of the Mullerian duct anomalies.

2) Associated congenital anomalies and the system they involve in the respective cases.

3) Optimum mode of management implied in the different diagnosed cases.

\section{Materials and Methods}

A longitudinal observational study was conducted at the EDEN HOSPITAL, Medical College, Kolkata between the time period from September 2008 to July 2009. Among more than 1000 patients reporting in the outpatient department within the above mentioned time period, 19 cases were found to be suffering from Mullerian developmental defect \{diagnosed through previous clinical history, physical examination, radiological scans (mainly magnetic resonance imaging) and diagnostic laparoscopy $\}$ and hence were included in the study.

The study was multiparametric in design. It focused on multiple parameters of an individual case. The study focused on the chief complaint of the cases when they presented themselves at the outpatients department \& hence latter classified into 3 major groups. The age at presentation was also put into record for the purpose of age level stratification. The positive clinical findings and detailed investigation reports were taken into account with the aim of formulating the final diagnosis for the case. Finally the optimum mode of management was designed for the individual cases and their outcome were also evaluated in the serial follow up at outpatient department for a period of 1 year.

\section{Results and Analysis}

- Among the 19 cases which presented in the outpatient department, the most common complaint among them was abdominal pain followed by absence of menarchy \& inability to conceive (Table 1) (Photos 1-11).

- The patients who were enrolled in the study mostly belonged to the age group of 15 - 17 years, followed by the age group of 18 - 20 yrs \& age group of 21 - 23 yrs (Table 2).

- Among the cases presenting as absence of menarchy, the most common diagnosis was presence of transverse vaginal septum in lower vagina (obstructed type) which was treated with excision of the septum, mould 


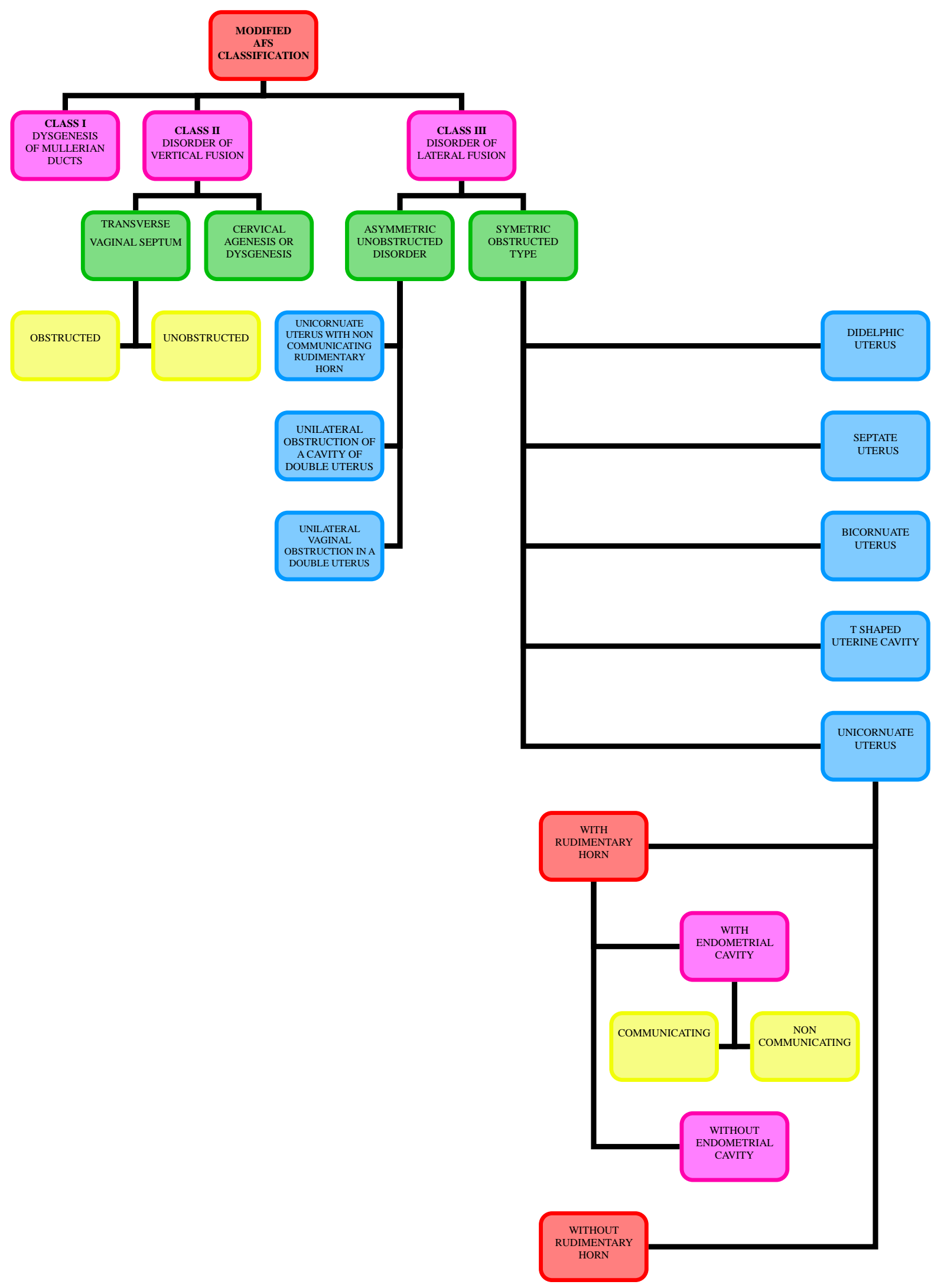

Figure 2. Modified AFS classification of Mullerian abnormalities [3]. 


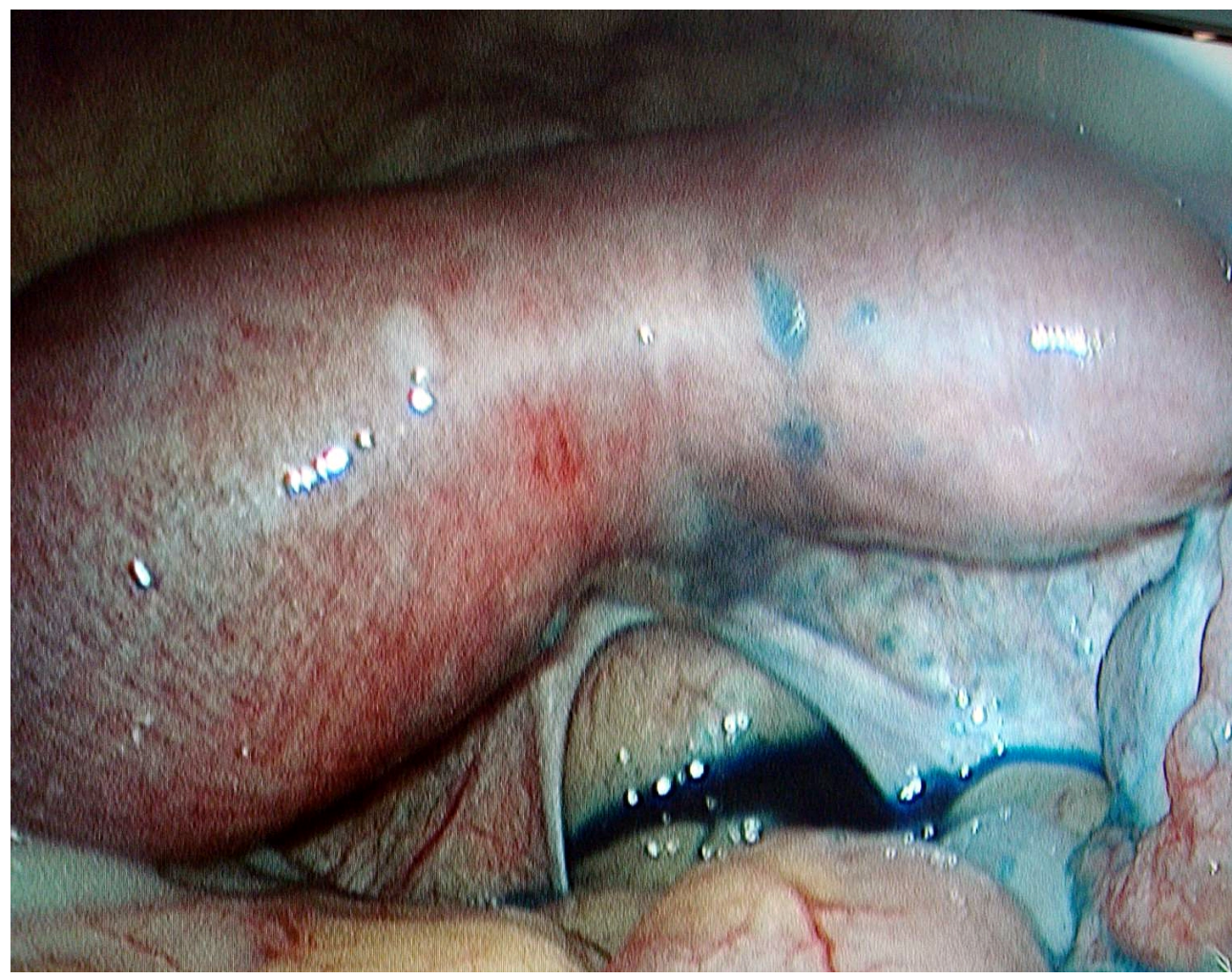

Photo 1. Pt. 18 (laparoscopic appearance)—complete bicornuate uterus with complete longitudinal vaginal septum.

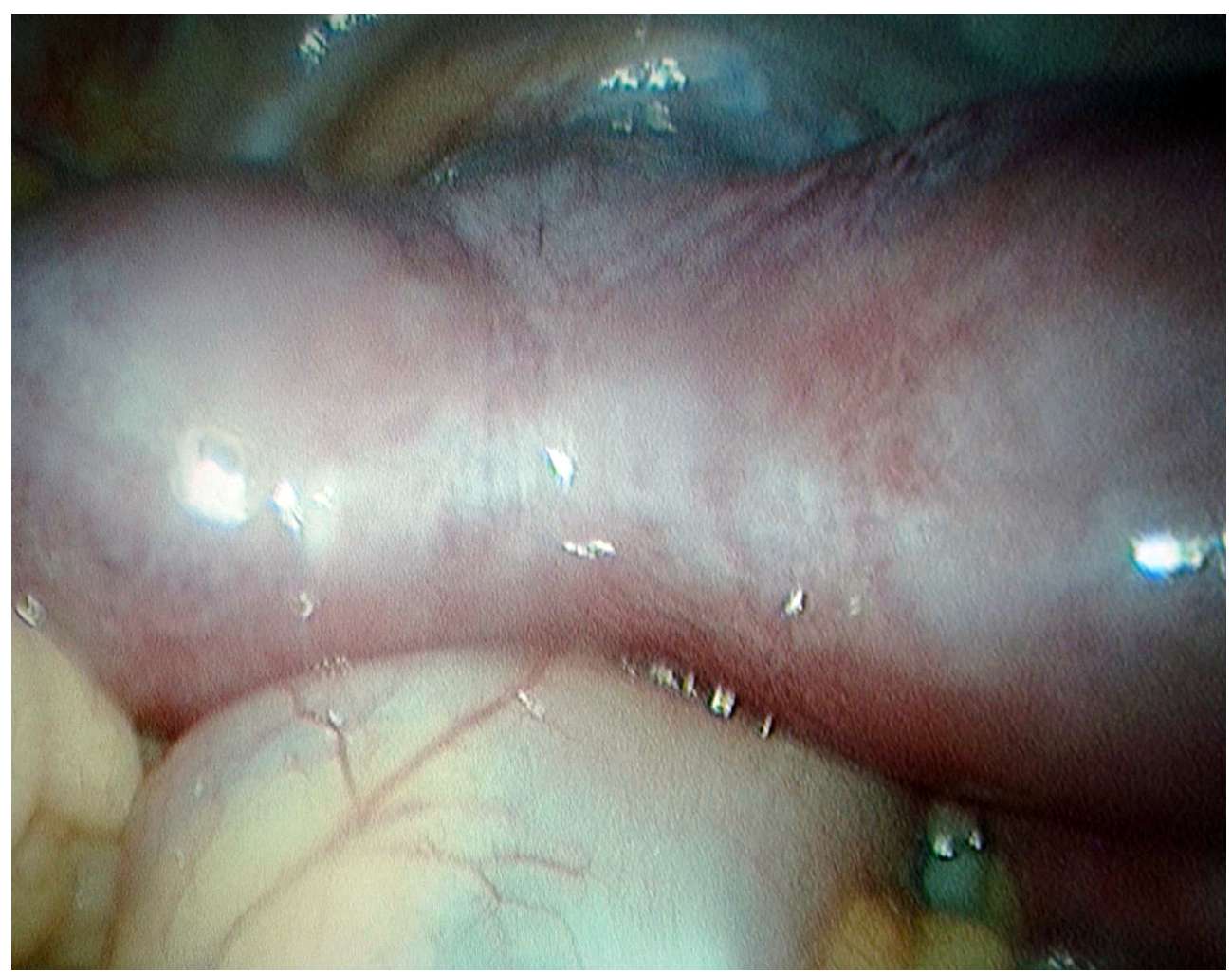

Photo 2. Pt. 19 (laparoscopic appearance)-bicornuate uterus. 


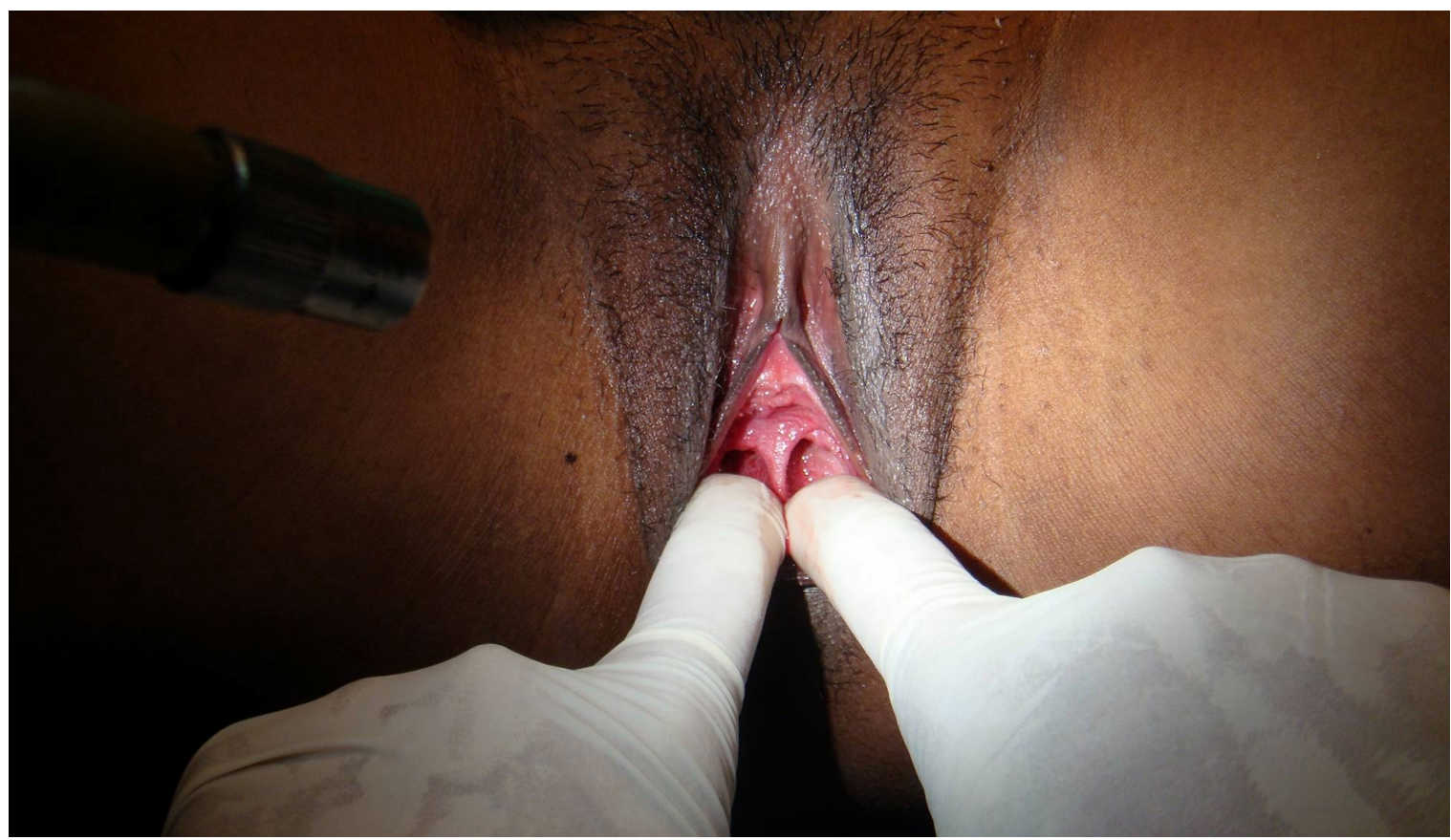

Photo 3. Pt. 18 (per vaginal appearance) —-partial septate uterus with complete longitudinal vaginal septum.

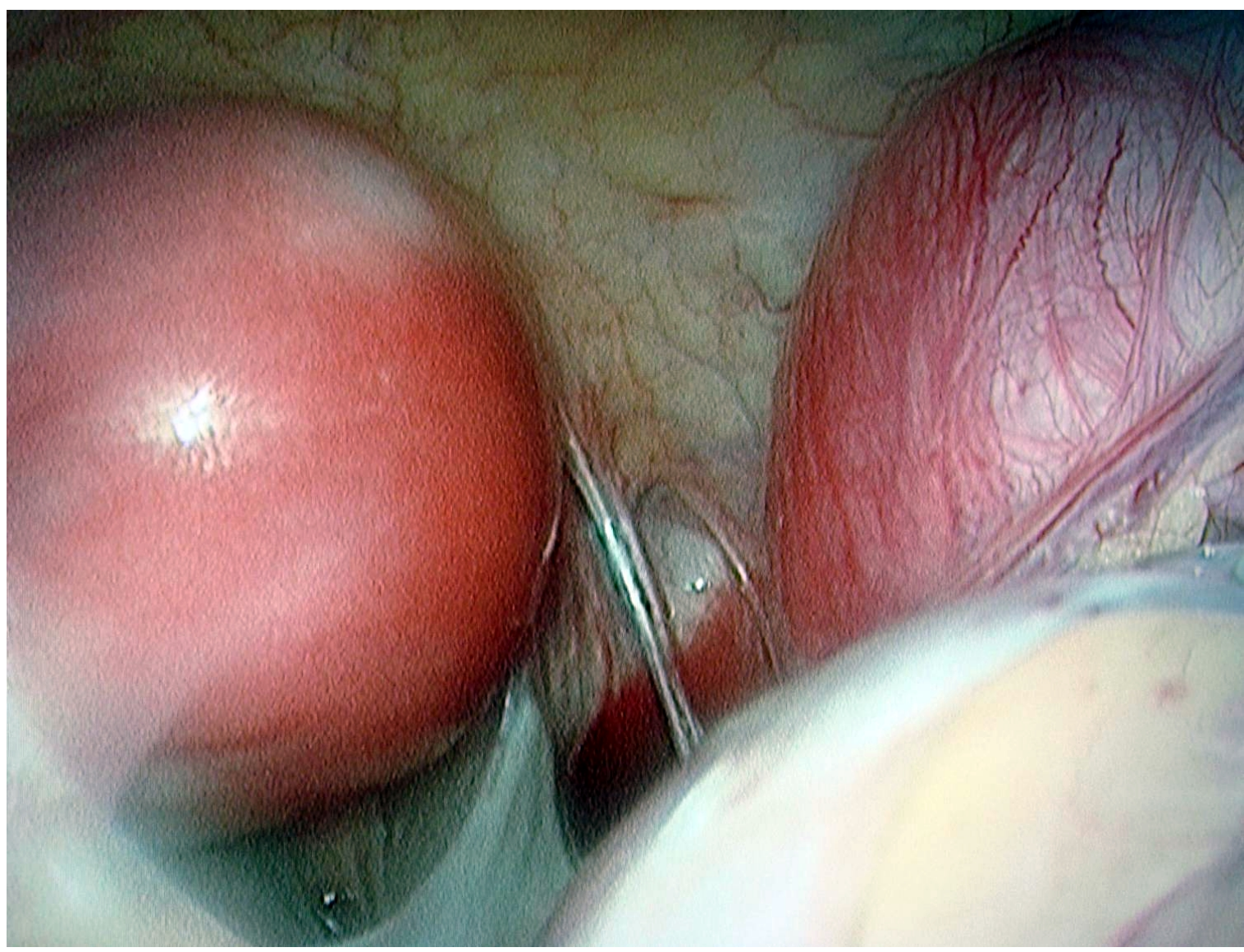

Photo 4. Pt. 8 (laparoscopic appearance) — unicornuate uterus with non-communicating functional horn and I/L chocolate cyst. 


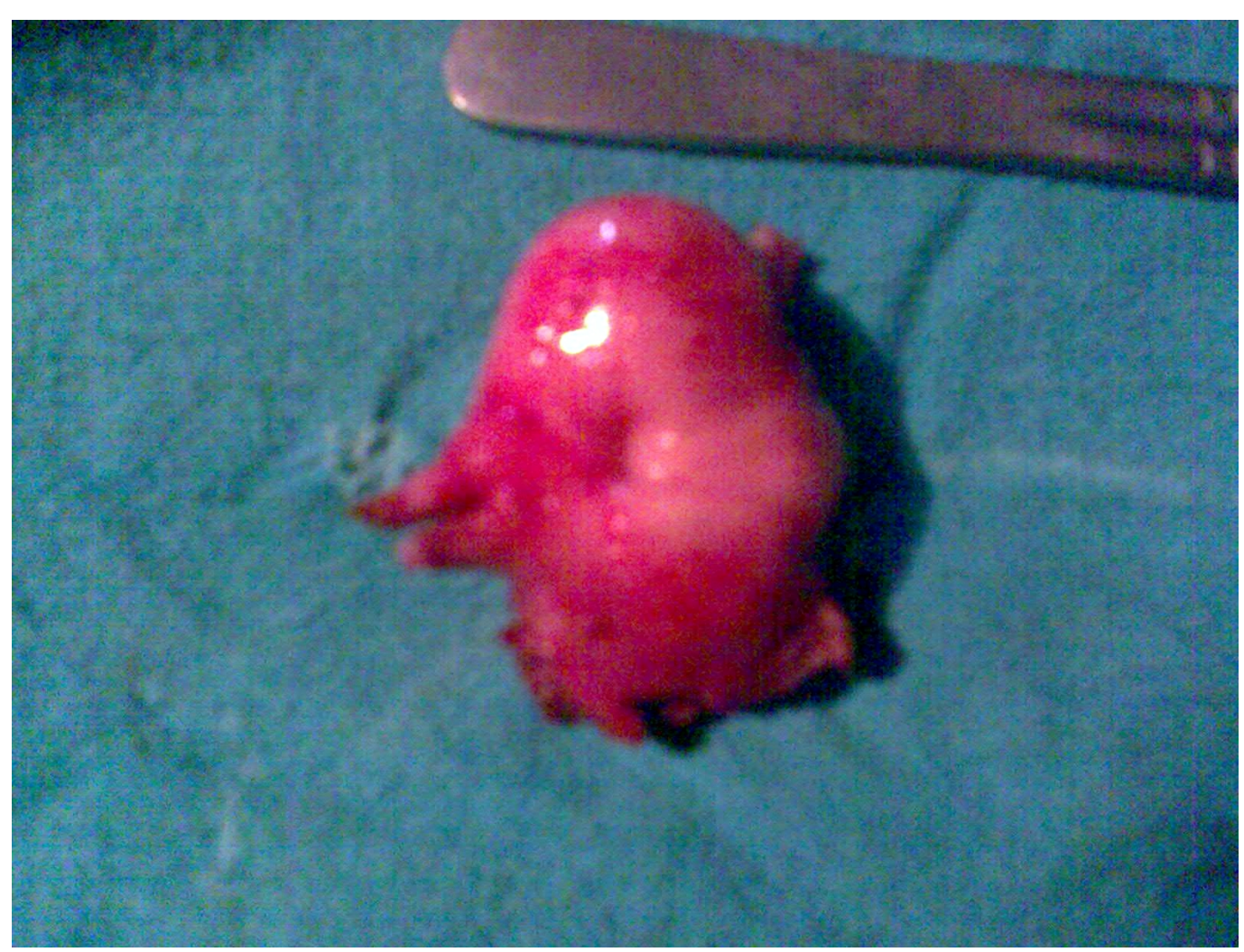

Photo 5. Pt. 8 - excised non-communicating uterine horn.

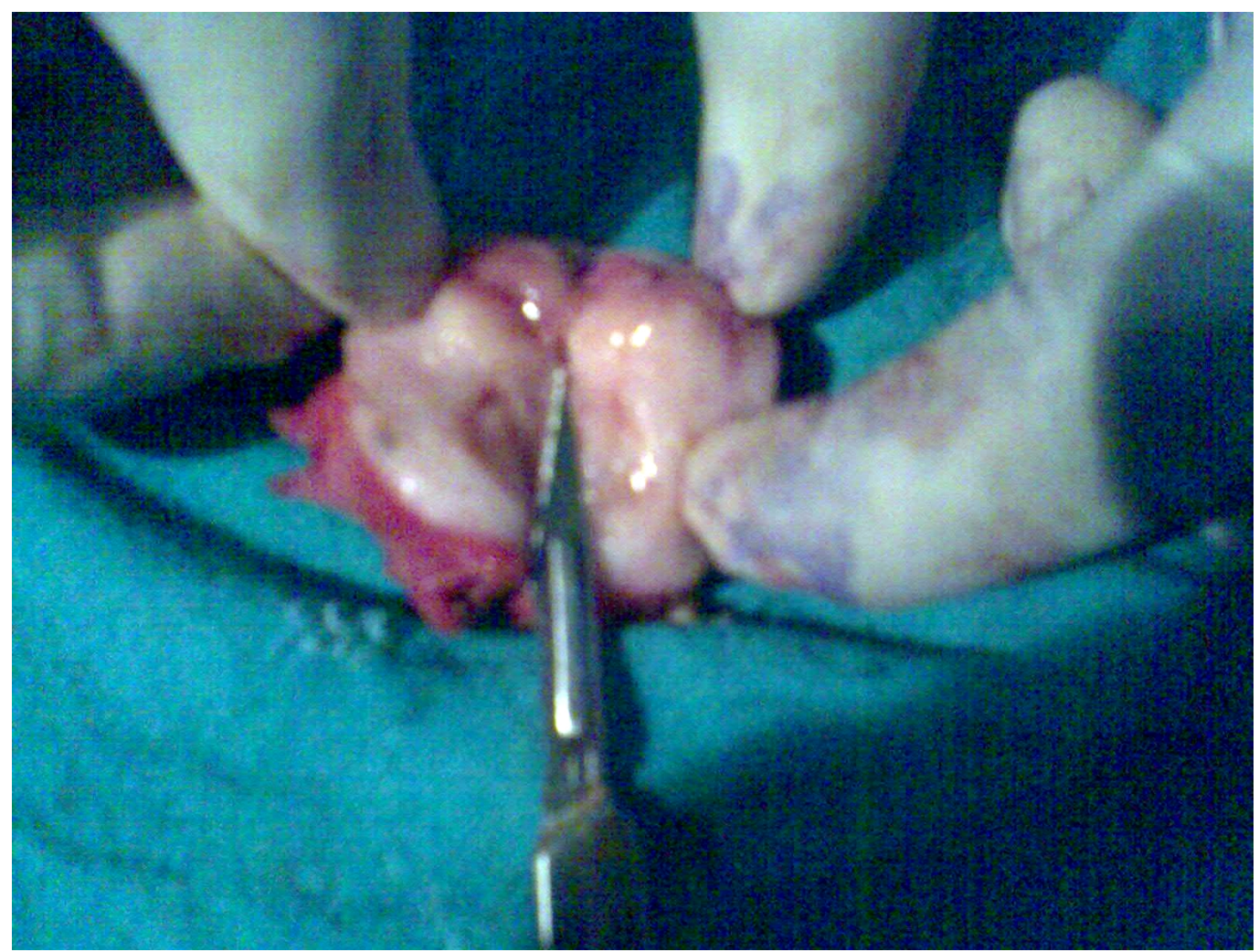

Photo 6. Pt. 8-functional endometrium within non communicating horn. 


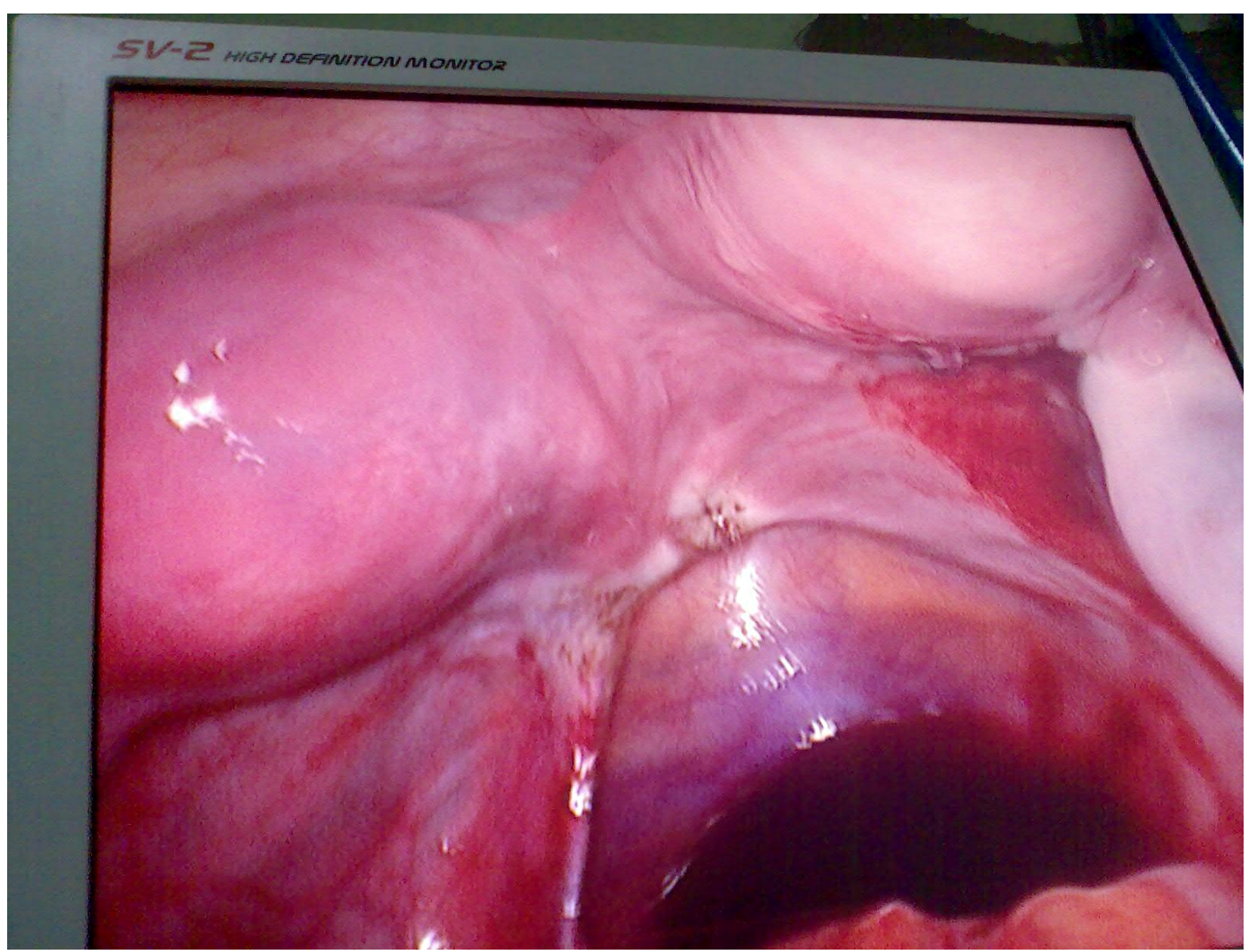

Photo 7. Pt. 7 (laparoscopic appearance)—unicornuate uterus with non communicating rudimentary horn.

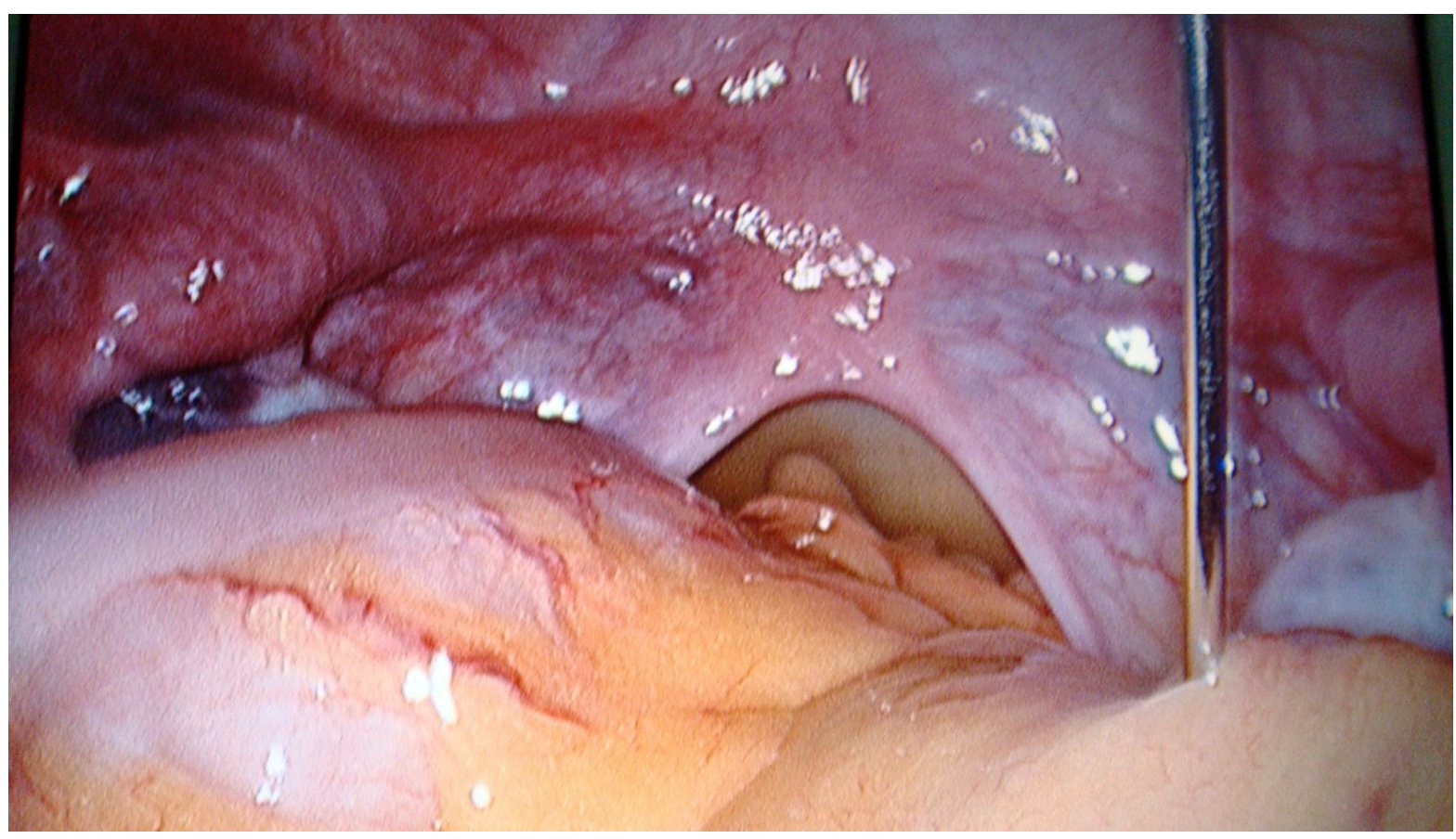

Photo 8. Pt. 5 (laparoscopic appearance)—dysgenesis of Mullerian ducts. 


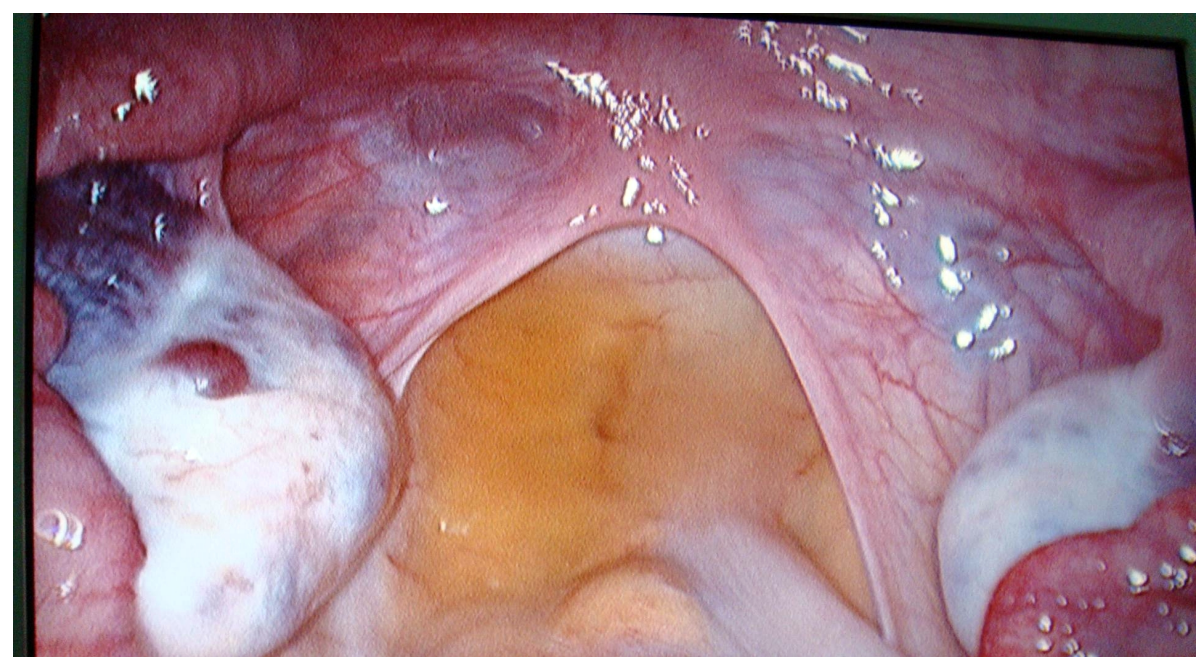

Photo 9. Pt. 6 (laparoscopic appearance)—dysgenesis of Mullerian ducts.

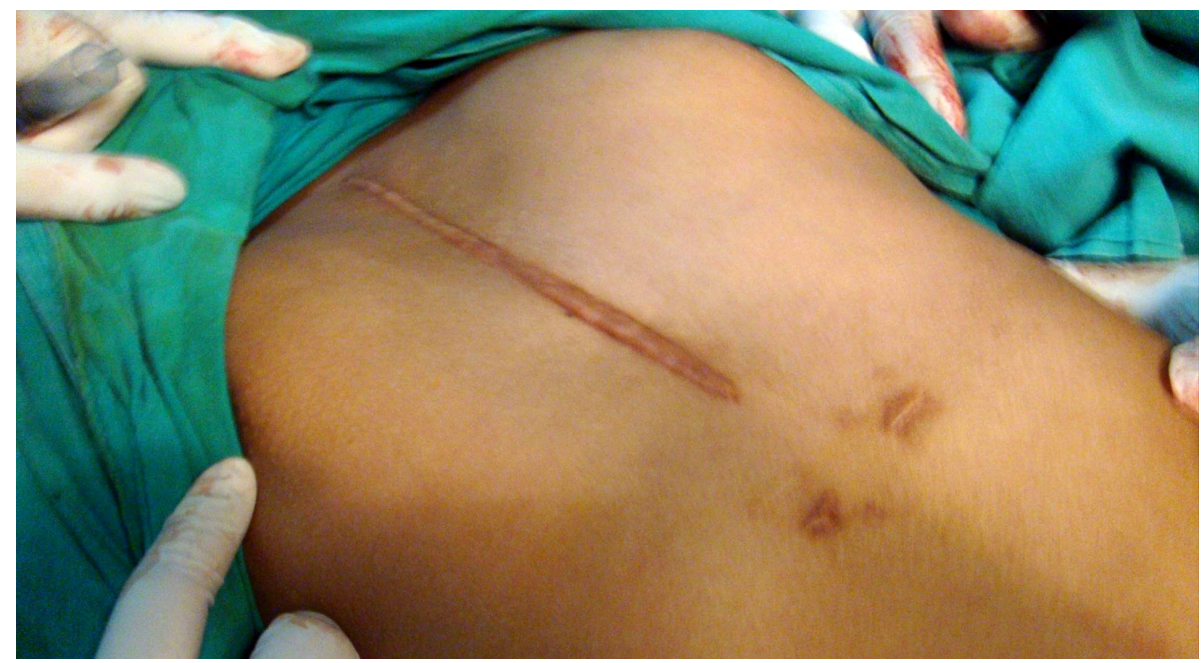

Photo 10. Pt. 8 - scar of previous sternotomy.

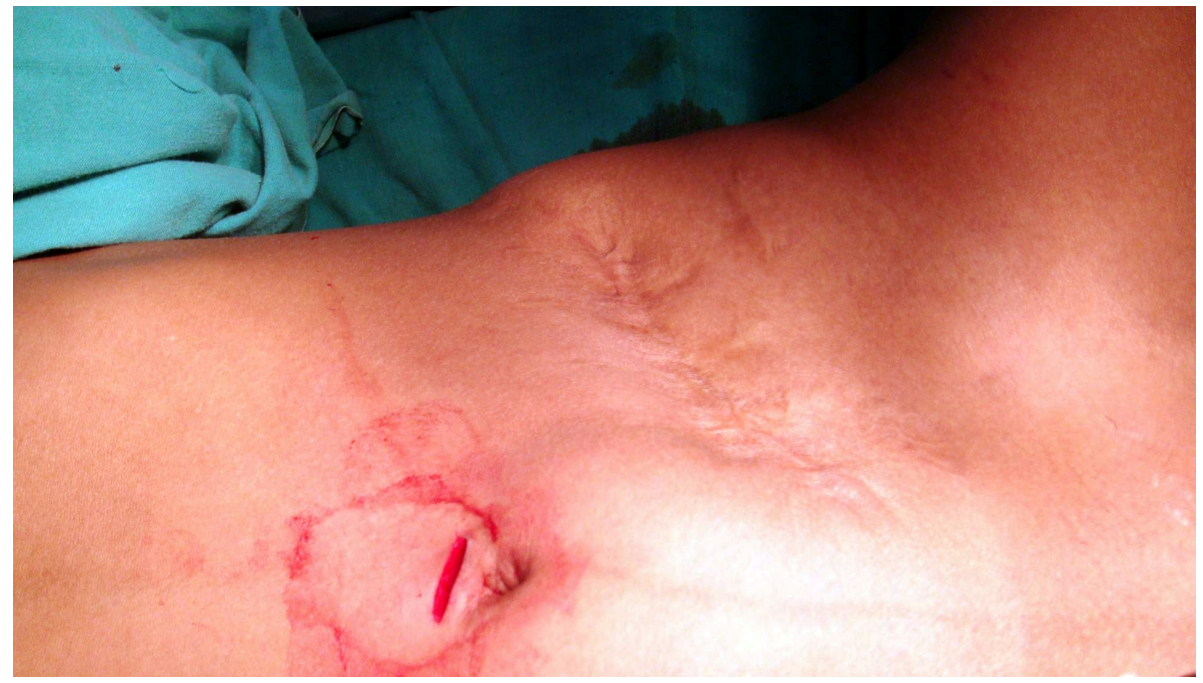

Photo 11. Pt. 8-scar of previous posterior sagittal anorectoplasty. 
Table 1. Distribution of cases based on chief complaint.

\begin{tabular}{ccc}
\hline CHIEF COMPLAINT & NUMBER OF CASES & PERCENTAGE \\
\hline Abdominal pain & 7 & $37 \%$ \\
Absence of menarchy & 6 & $31.5 \%$ \\
Inability to conceive & 6 & $31.5 \%$ \\
\hline
\end{tabular}

Table 2. Distribution of cases based on age group.

\begin{tabular}{ccc}
\hline AGE GROUP & NUMBER OF CASES & PERCENTAGE \\
\hline $15-17$ yrs & 10 & $52.6 \%$ \\
$18-20$ yrs & 5 & $26.4 \%$ \\
$21-23$ yrs & 4 & $21 \%$ \\
\hline
\end{tabular}

Table 3. Distribution of cases which presented with absence of menarchy.

\begin{tabular}{|c|c|c|c|c|}
\hline CASES & AGE & DIAGNOSIS & TREATMENT & MENSTRUA TION (Y/N) \\
\hline Pt. 1, Pt. 2, Pt. 3 & $15,16,16$ & $\begin{array}{l}\text { Transverse vaginal septum in lower } \\
\text { vagina (obstructed) }\end{array}$ & $\begin{array}{l}\text { Excision, mould insertion } \\
\text { with vaginal dilatation }\end{array}$ & $\mathrm{Y}$ \\
\hline Pt. 4 & 15 & $\begin{array}{l}\text { Transverse vaginal septum in upper } \\
\text { vagina (obstructed) }\end{array}$ & $\begin{array}{l}\text { Excision, mould insertion } \\
\text { with vaginal dilatation }\end{array}$ & $\mathrm{Y}$ \\
\hline Pt. 5 & 17 & Dysgenesis of Mullerian ducts & McIndoe’s vaginoplasty & $\mathrm{N}$ \\
\hline Pt. 6 & 16 & Dysgenesis of Mullerian ducts & McIndoe’s vaginoplasty & $\mathrm{N}$ \\
\hline
\end{tabular}

Table 4. Distribution of cases presenting with abdominal pain.

\begin{tabular}{|c|c|c|c|c|}
\hline CASES & AGE & DIAGNOSIS & TREATMENT & $\begin{array}{c}\text { RELIEF FROM } \\
\text { ABDOMINAL PAIN (Y/N) }\end{array}$ \\
\hline Pt. 7 & 18 & $\begin{array}{l}\text { Unicornuate uterus with non } \\
\text { communicating rudimentary horn }\end{array}$ & $\begin{array}{l}\text { Laparoscopic excision of the } \\
\text { non communicating horn }\end{array}$ & $\mathrm{Y}$ \\
\hline Pt. 8 & 18 & $\begin{array}{l}\text { Unicornuate uterus with non } \\
\text { communicating functional horn } \\
\text { and I/L chocolate cyst }\end{array}$ & $\begin{array}{l}\text { Laparoscopic excision of functional } \\
\text { uterine horn and chocolate cyst }\end{array}$ & $\mathrm{Y}$ \\
\hline Pt. 9 & 17 & $\begin{array}{l}\text { Cervical agenesis along with } \\
\text { functional uterine corpus and } \\
\text { short vaginal pouch }\end{array}$ & $\begin{array}{l}\text { McIndoe's vaginoplasty with } \\
\text { patient counselling }\end{array}$ & $\mathrm{N}$ \\
\hline $\begin{array}{l}\text { Pt. 10, Pt. 11, } \\
\text { Pt. 12, Pt. } 13\end{array}$ & $\begin{array}{l}17,16 \\
18,17\end{array}$ & $\begin{array}{l}\text { Transverse vaginal septum with } \\
\text { hematocolpos/hematometra }\end{array}$ & $\begin{array}{l}\text { Excision of septum with drainage } \\
\text { of hematocolpos/hematometra }\end{array}$ & $\mathrm{Y}$ \\
\hline
\end{tabular}

Table 5. Distribution of cases presenting with inability to conceive.

\begin{tabular}{|c|c|c|c|c|}
\hline CASE & AGE & DIAGNOSIS & TREATMENT & CONCEPTION (Y/N) \\
\hline Pt. 14 & 21 & $\begin{array}{l}\text { Partial septate uterus with complete } \\
\text { longitudinal vaginal septum }\end{array}$ & $\begin{array}{l}\text { Excision of longitudinal } \\
\text { vaginal septum }\end{array}$ & $\mathrm{Y}$ \\
\hline Pt. 15, Pt. 16, Pt. 17 & $20,21,20$ & Dysgenesis of Mullerian ducts & McIndoe’s vaginoplasty & $\mathrm{N}$ \\
\hline Pt. 18 & 20 & $\begin{array}{l}\text { Bicornuate uterus with complete } \\
\text { longitudinal vaginal septum }\end{array}$ & $\begin{array}{l}\text { Utriculoplasty and excision } \\
\text { of longitudinal septum }\end{array}$ & $\mathrm{Y}$ \\
\hline Pt. 19 & 21 & Bicornuate uterus & Metroplasty & $\mathrm{Y}$ \\
\hline
\end{tabular}

Table 6. Presence of associated anomaly among the cases in discussion.

\begin{tabular}{cccc}
\hline SYSTEM & ASSOCIATED ABNORMALITY FOUND IN NUMBER OF CASES & PERCENTAGE (OF TOTAL) \\
\hline Renal & 4 & $21 \%$ \\
Cardiac & 2 & $10 \%$ \\
Gastrointestinal & 1 & $5 \%$ \\
\hline
\end{tabular}


insertion along with regular vaginal dilatation. There was a lone case of transverse vaginal septum of upper vagina which was also treated with excision of the septum, mould insertion and regular vaginal dilatation. There were two cases of dysgenesis of Mullerian ducts which were later treated with McIndoes vaginoplasty. Among 6 cases presenting with absence of menarchy 4 cases successfully resumed into regular menstrual cycles (Table 3).

- Among the cases presenting with the chief complaint of abdominal pain, the most common diagnosis encountered was transverse vaginal septum with hematocolpos/hematometra. These cases were treated successfully with excision of septum followed by drainage of hematocolpos/hematometra. There was a single interesting case of unicornuate uterus with non communicating rudimentary horn which was successfully treated with laparoscopic excision of the rudimentary horn. A single case of unicornuate uterus with non communicating functional horn with ipsilateral chocolate cyst was also encountered. This particular case was treated with laparoscopic excision of functional horn and chocolate cyst along with closure of agenetic vagina. There was a lone case of cervical agenesis along with functional uterine corpus and short vaginal pouch which was treated with McIndoe's vaginoplasty along with proper patient counseling (Table 4).

- Among the cases presenting with the chief complaint of inability to conceive, the most common diagnosis came out to be of dysgenesis of Mullerian ducts which were treated McIndoe's vaginoplasty. A single case was found to be suffering from partial septate uterus with complete longitudinal vaginal septum, which was treated with excision of longitudinal septum. This patient conceived within 6 months of treatment. There was a solitary case of complete bicornuate uterus with complete longitudinal vaginal septum. This patient was treated with utriculoplasty and excision of the longitudinal septum. This patient also conceived within 6 months of surgery. There was also a lone case of complete bicornuate uterus who was treated with metroplasty operation and the patient conceived within 6 months of treatment (Table 5).

- Among the associated abnormalities encountered in the 19 diagnosed cases, 4 of them were found to have associated abnormalities worth mentioning (Table 6).

Pt. 13, who was with 17 yrs of age with chief complaint of cyclical abdominal pain was found to have a complete transverse vaginal septum with hematocolpos. Associated finding in this case was absence of right kidney and ureter.

Pt. 8, who was 19 yrs old presented with chief complaint of abdominal pain. She gave past history of high type rectal agenesis on the $2^{\text {nd }}$ day of birth and also ventricular septal defect repaired between 6 to 12 months of age. She also had an associated finding of absent right kidney and ureter and was diagnosed as a case of unicornuate uterus with non-communicating functional horn and I/L chocolate cyst. She also had ipsilateral absent right kidney and ureter.

Pt. 18, who was 20 yrs old presented with complaint of inability to conceive. Her final diagnosis came out to be of Bicornuate uterus with complete longitudinal vaginal septum. She also gave the history of ventricular septal defect repaired by posterior sagittal anorectoplasty at 14 yrs of age. She also had absent left kidney.

Pt. 1, who was 16 yrs old presented with complaints of absence of menarchy was diagnosed as transverse vaginal septum in lower vagina (obstructed). She was also found to be suffering from left sided renal agenesis.

\section{Conclusions}

- Out of approximately 6000 gynaecological cases seen at the outpatients department 19 cases were found to be suffering from Mullerian abnormalities.

- Most of them presented at an early age group of 15 - 17 yrs.

- Commonest presenting complaint was cyclical abdominal pain.

- Most common specific final diagnosis was transverse vaginal septum.

- Most common associated anomaly was renal.

- Treatment modality was mostly individualized according to the case diagnosed.

\section{Discussion}

In this particular study the incidence of Mullerian abnormalities was found to be of approximately 3 out of 1000 cases presenting with gynaecological complaints in the outpatient department. The actual prevalence rate for Mullerian anomalies varied from 1 in 4000 to 1 in 10,000 [4]. The higher rate of reporting in the present study was mainly due to higher rate of referral from the primary and secondary tier healthcare as these cases needed 
specific individualized management which was possible only in tertiary level healthcare. The typical age of presentation was mostly found in between 15 - 17 yrs. In another notable study by Mane et al., the mean age of presentation was typically at 17 years [5]. In another study done by Reindollar et al., it has been shown that the cases of Mullerian abnormalities typically presented at adolescent age group [6]. In this particular study, around $80 \%$ of the total patients presented belonged to the adolescent age group (10 - $19 \mathrm{yrs})$. The patients mostly presented with chronic abdominal pain (37\%), closely followed by primary amenorrhea (31.5\%) and inability to conceive (31.5\%). In the study done by Jeon et al., these again were the three most common presenting complaints with incidence rate of $10.8 \%, 12.4 \%$ and $8.6 \%$ respectively [7]. Among the cases presenting with primary amenorrhoea, the most common final diagnosis was transverse vaginal septum (66.6\%) followed by dysgenesis of Mullerian ducts. All the cases of transverse vaginal septum were treated successfully whereas in the cases of Mullerian dysgenesis only McIndoe's vaginoplasty could provide some cosmetic advantages. The results were found to be quite similar of those of the study done by Parikh RM et al., where they also cited transverse vaginal septum and dysgenesis of the Mullerian ducts as the main 2 causes of primary amenorrhoea while dealing with 14 patients of Mullerian abnormality [8]. Among the cases presenting with abdominal pain, the most common final diagnosis once again zeroed to transverse vaginal septum (57\%) with hematocolpos/hematometra. These cases were treated successfully with excision of septum followed by drainage of hematocolpos/hematometra. This result corresponds well with the findings of Deligeoroglou et al., where 4 patients of transverse vaginal septum presented with hypogastric abdominal pain and were treated accordingly [9]. The second most common cause for abdominal pain turned out to be unicornuate uterus with non-communicating horn (2 cases). The cause of pain in case of a rudimentary horn was most probably due to distension of the horn. This finding again goes in the same direction as that of Rusen Atmaca et al., where a similar case presented with acute abdominal pain and was treated with excision of rudimentary horn [10]. There was a single case encountered of cervical agenesis with functional uterine corpus presenting with abdominal pain. This finding corresponds with that of El Gharib et al., where they also encountered a similar case of cervical agenesis which was treated with abdominal surgical approach [11]. Among the cases presenting with the chief complaint of inability to conceive, the most common final diagnosis was dysgenesis of Mullerian duct which could be treated only with McIndoe's vaginoplasty with patient counseling. The other cases encountered were of partial septate and bicornuate uterus, all of whom conceived after surgical correction of congenital defect. The scenario was somehow similar to that of Grimbizis GF et al., where there was more than 50\% live birth rate reported after surgical correction of Mullerian abnormalities [12]. There was a single case of partial septate uterus with longitudinal septum of vagina which was treated successfully with excision of septum. This patient conceived within 6 months of treatment. The result was quite similar to the study done by Pai et al., where $45 \%$ of patients conceived within one year of septum resection [13]. There were 2 cases of bicornuate uterus included in the present study, both of whom conceived after unification operative measures. This result goes in coordination with the study done by Maneschi et al., where there was improved live birth rate from $0 \%$ to $80 \%$ and a decreased miscarriage rate from $64 \%$ to $20 \%$ after surgical correction of bicornuate uterus [14]. When the zone of associated abnormalities was searched, it was found that renal system defects were the most common defects associated with the system. According to the work done by Li S et al., there was an association of $30 \%$ between renal agenesis and Mullerian agenesis [15]. There was an association of rectal agenesis in a single case of unicornuate uterus. According to the study done by Peter Oppelt of Germany in 2007, there is an association of rectal atresia with Mullerian abnormalities which is about $2 \%$ [16]. There were two cases of ventricular septal defect associated with unicornuate uterus. Pittcock and colleagues reported a substantial incidence of cardiac defects (16\%) when reviewing a group of 25 patients with Mullerian abnormalities [17].

\section{References}

[1] Rock, J.A. and Jones, H.W. (2011) Te Linde’s Operative Gynaecology. 10th Edition, LWW, 544.

[2] Rackow, B.W. and Arici, A. (2007) Reproductive Performance of Women with Mullerian Anomalies. Current Opinion in Obstetrics and Gynecology, 19, 229-237. http://dx.doi.org/10.1097/GCO.0b013e32814b0649

[3] Rock, J.A. and Jones, H.W. (2011) Te Linde’s Operative Gynaecology. 10th Edition, LWW, 540.

[4] Evans, T.N., Poland, M.L. and Boving, R.L. (1981) Vaginal Malformations. American Journal of Obstetrics Gynecology, 141, 910-920.

[5] Mane, S.B. and Shastri, P. (2010) Our 10-Year Experience of Variable Müllerian Anomalies and Its Management. Pe- 
diatric Surgery International, 26, 795-800. http://dx.doi.org/10.1007/s00383-010-2640-3

[6] Reindollar, R.H., Byrd, J.R. and McDonough, P.G. (1981) Delayed Sexual Development: A Study of 252 Patients. American Journal of Obstetrics Gynecology, 140, 371-380.

[7] Jeon, G.H., Park, Y.R. and Shin, Y.J. (2010) Clinical Characteristics of Women with Müllerian Anomaly: Twenty Years of Experience at Asan Medical Center. Korean Journal of Obstetrics Gynecology, 53, 626-632. http://dx.doi.org/10.5468/kjog.2010.53.7.626

[8] Parikh, R.M., et al. (2013) Mullerian Anomalies: A Cause of Primary Amenorrhea. International Journal of Reproduction, Contraception, Obstetrics and Gynecology, 2, 393-397.

[9] Deligeoroglou, E., Iavazzo, C., Sofoudis, C., Kalampokas, T. and Creatsas, G. (2012) Management of Hematocolpos in Adolescents with Transverse Vaginal Septum. Archives of Gynecology and Obstetrics, 285, 1083-1087. http://dx.doi.org/10.1007/s00404-011-2114-4

[10] Atmaca, R. and Germen, A.T. (2005) Acute Abdomen in a Case with Noncommunicating Rudimentary Horn and Unicornuate Uterus. JSLS, 9, 235-237.

[11] EL-Gharib, M.N. and Awara, A.M. (2012) Abdominal Surgical Management of Partial Cervical Agenesis in a Virgin. Medical Practice and Review, 3, 5-8.

[12] Grimbizis, G.F., Camus, M., Tarlatzis, B.C., et al. (2001) Clinical Implications of Uterine Malformations and Hysteroscopic Treatment Results. Human Reproduction Update, 7, 161-174. http://dx.doi.org/10.1093/humupd/7.2.161

[13] Pai, H.D. and Kundnani, M.T. (2009) Reproductive Performance after Hysteroscopic Metroplasty in Women with Primary Infertility and Septate Uterus. Journal of Gynecological Endoscopy and Surgery, 1, 17-20.

[14] Maneschi, F., Marana, R., Muzii, L. and Mancuso, S. (1993) Reproductive Performance in Women with Bicornuate Uterus. Acta Europaea Fertilitatis, 24, 117-120.

[15] Li, S., Qayyum, A., Coakley, F.V. and Hricak, H. (2000) Association of Renal Agenesis and Mullerian Duct Anomalies. Journal of Computer Assisted Tomography, 24, 829-834. http://dx.doi.org/10.1097/00004728-200011000-00001

[16] Oppelt, P., Von Have, M., Paulsen, M., Strissel, P.L., Strick, R., Brucker, S., Wallwiener, D. and Beckmann, M.W. (2007) Female Genital Malformations and Their Associated Abnormalities. Fertility and Sterility, 87, 335-342.

[17] Pittock, S.T., Babovic-Vuksanovic, D. and Lteif, A. (2005) Mayer-Rokitansky-Küster-Hauser Anomaly and Its Associated Malformations. American Journal of Medical Genetics Part A, 135, 314-316.

http://dx.doi.org/10.1002/ajmg.a.30721 
Scientific Research Publishing (SCIRP) is one of the largest Open Access journal publishers. It is currently publishing more than 200 open access, online, peer-reviewed journals covering a wide range of academic disciplines. SCIRP serves the worldwide academic communities and contributes to the progress and application of science with its publication.

Other selected journals from SCIRP are listed as below. Submit your manuscript to us via either submit@scirp.org or Online Submission Portal.
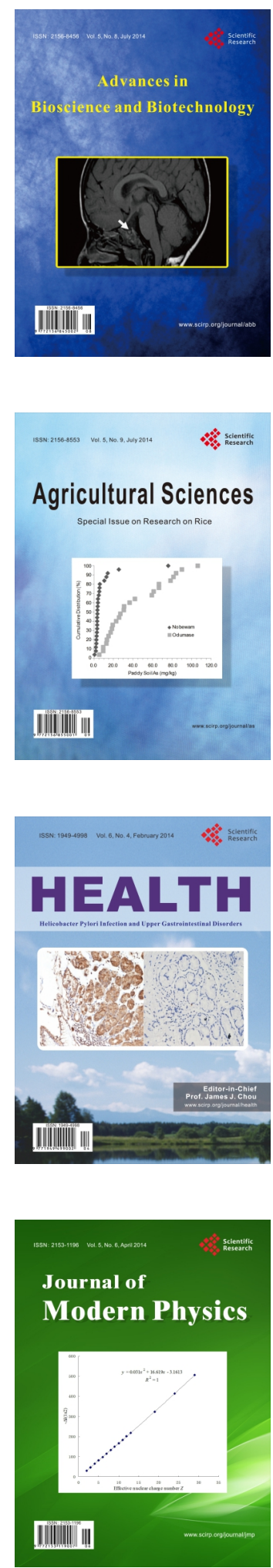
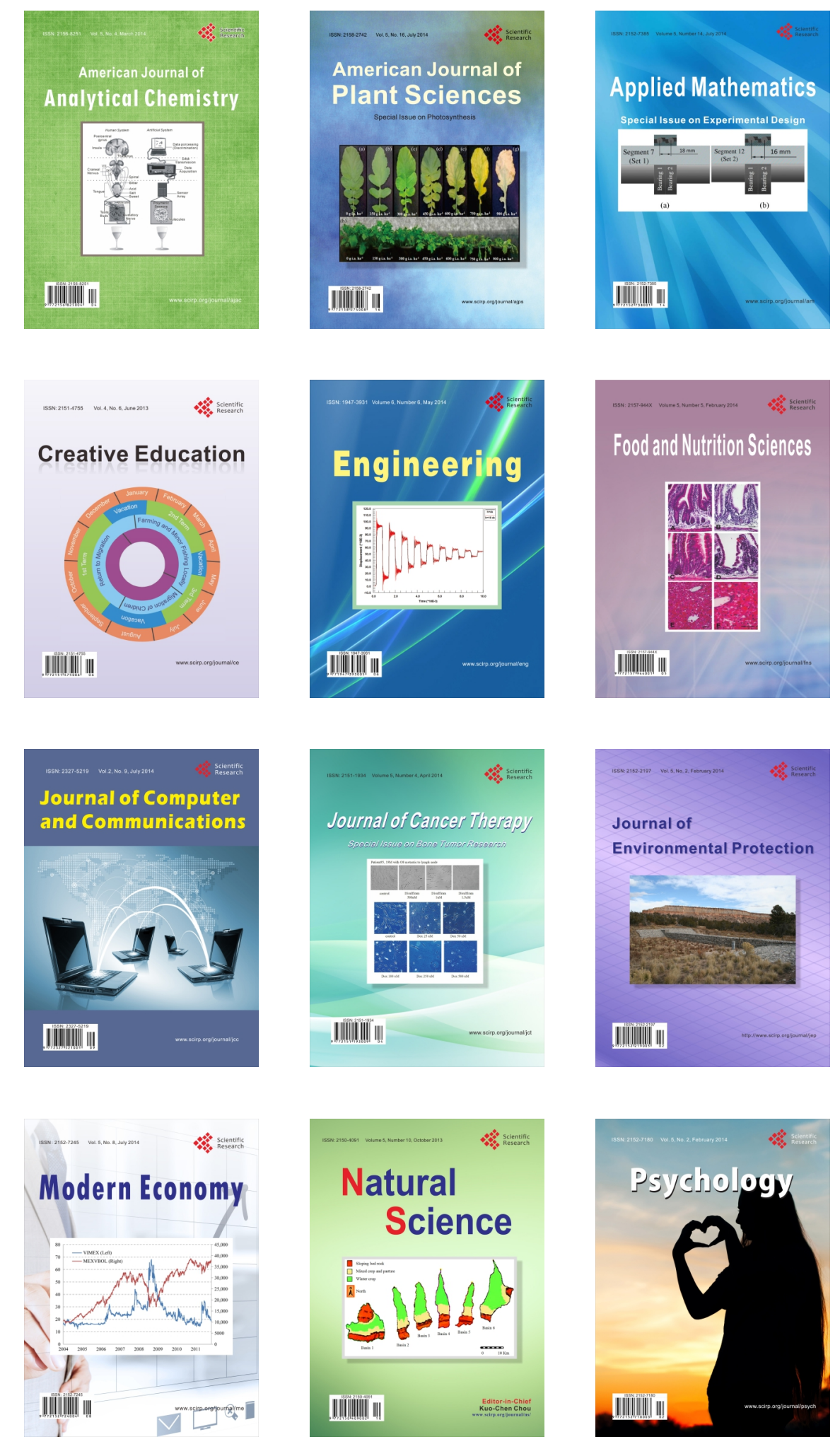